

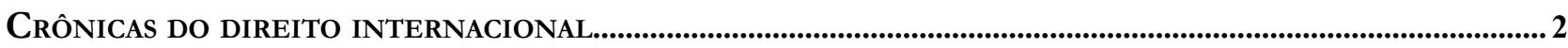

Nitish Monebhurrun

Alice Rocha da Silva

Julia Motte-Baumvol

Rafael Freitas de Oliveira

Roberta Greco

CRÔNICAS DO DIREITO INTERNACIONAL DOS INVESTIMENTOS .11

Nitish Monebhurrun

Reconhecimento E ExecuÇão de Sentenças Estrangeiras: anÁlise do projeto Em andamento na Conferência da Haia de Direito Internacional Privado

Nadia de Araujo

Fabrício Bertini Pasquot Polido

Os CASAMENTOS E AS PARCERIAS ENTRE PESSOAS DO MESMO SEXO NO DIREITO INTERNACIONAL PRIVAdO BRASILEIRO: ASPECTOS TRANSNACIONAIS DAS FAMÍLIAS CONTEMPORÂNEAS.

Bruno Rodrigues de Almeida

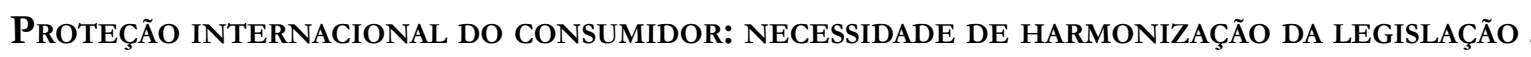
54

Héctor Valverde Santana

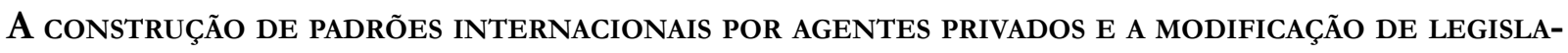
Ção NACIONAL: ALTERAÇÃo do PADRÃo DE CONTABILIDADE PARA EMPRESÁRIOS NO BRASIL.

Cleíse Nascimento Martins Costa

THE DEBATE ON COMPANIES' LIABILITY FOR INTERNATIONAL ENVIRONMENTAL DAMAGES: A COMPARISON BETWEEN THE JURISDiCTIONAL RULES OF THE EUROPEAN UNION AND THE UNITED STATES

Carina Costa de Oliveira

DesenVOlVIMENTO E APLICAÇÃo DA TEORIA dos VíNCUlOS MAIS ESTREITOS NO DIREITO INTERNACIONAL PRIVADO: POR UMA REDISCUSSÃO DO MÉTODO DE SOLUÇÃO DO CONFLITO DE LEIS 101

Jamile Bergamaschine Mata Diz

Rodrigo Vaslin Diniz

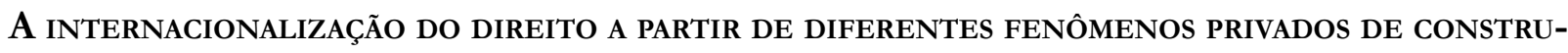
ÇÃO NORMATIVA 117

Fernando Lopes Ferraz Elias 
Leilane Serratine Grubba

Human TRAFFicking: IDENTIFYING FORCED LABOR IN MULTINATIONAL CORPORATIONS \& THE IMPLICATIONS OF LIABILITY

Tara M. Parente

Aplicação dos princípios UNIDROIT no Plano Brasil maior: o SUPRIMENTO de UMA lacuna NA POLÍTICA BRASILEIRA DE DESENVOLVIMENTO ECONÔMICO

Guilherme Freire de Melo Barros

Marcelle Franco Espíndola Barros

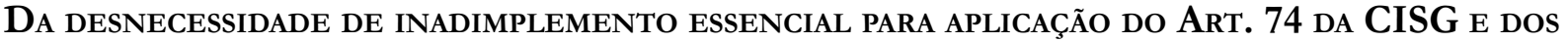
DANOS EFETIVAMENTE RECUPERÁVEIS

Renata Caroline Kroska

ESSAY ON UNEQUAL TREATIES AND MODERNITY THROUGH THE EXAMPLE OF BILATERAL INVESTMENT TREATIES

Nitish Monebhurrun

CONCEITOS DE RELAÇÕES INTERNACIONAIS E TEORIA DO DIREITO DIANTE DOS EFEITOS PLURALISTAS DA GLOBALIZAÇÃO: GOVERNANÇA GLOBAL, REGIMES JURÍDICOS, DIREITO REFLEXIVO, PLURALISMO JURÍDICO,

CORREGULAÇÃO E AUTORREGULAÇÃO . 216

Gabriela Garcia Batista Lima

\section{Outros Temas}

CONVENÇão SOBRE OS DIREITOS DAS PESSOAS COM DEFICIÊNCIA: COMO "INVISÍVEIS" CONQUISTARAM SEU ESPAÇO .230

Luana da Silva Vittorati

Matheus de Carvalho Hernandez 


\title{
A internacionalização do direito a partir de diferentes fenômenos privados de construção normativa*
}

\author{
The internationalisation of law since different \\ private phenomena of normative construction
}

Fernando Lopes Ferraz Elias ${ }^{* *}$

\section{Resumo}

O escopo deste artigo é analisar manifestações não estatais de produção normativa do direito pós-nacional. Inicialmente, ressaltamos a teoria das fontes do direito no contexto pós-nacional. Em seguida, analisamos o fenômeno da multiplicação de sujeitos de direito e de fontes normativas no plano internacional. Finalmente, perscrutamos a questão do reconhecimento das fontes jurídicas pósnacionais construídas por atores privados autônomos em relação à ação estatal. Concluímos que, fruto da confluência de normas, quer sejam públicas, quer sejam privadas, mesmo que oriundas de fenômenos marcadamente internos ou até mesmo extrajurídicos, no contexto pós-nacional hodierno, não há que se falar, exclusivamente, em um direito internacional público e em um direito internacional privado, uma vez que domínios jurídicos; (a exemplo da lex mercatoria, lex financeira, lex eletronica, lex desportiva, dentre outros); revelam conjuntos normativos produzidos por destacadas empresas privadas globais voltados à concretização de "interesses públicos". Contudo, a mera autonomia de "contatos sociais" é insuficiente para gerar compromissos juridicamente obrigatórios e vinculantes, pois, sem unidade, expressões jurídicas fragmentadas possuem liames tíbios. Portanto, o presente estudo é dotado de originalidade e limita-se a questões pertinentes à estrutura da ordem jurídica pós-nacional, especificamente, a natureza privada dos entes e das normas num cenário de internacionalização do direito. Despido de pretensões de exaurir o tema, o trabalho foca, entre outras, as diferenças quanto à formação e implementação do direito pós-nacional e do direito estatal.

Palavras-chave: Direito estatal. Direito internacional privado. Direito pósnacional. Entes privados. Internacionalização do direito.

\section{Abstract}

The scope of this article is to analyze non-state manifestations of normative production of the post-national law. First, we emphasize the theory of the sources

*Recebido em 11/05/2014 Aprovado em 16/05/2014

\footnotetext{
**Bacharel em Direito e Relações Internacionais pela PUC-SP, Mestre em Relações Internacionais pela UNISUL, Doutorando em Direito pelo UNICEUB. E-mail: flfe@ig.com.br
}

of law in post-national context. Then, we analyze the phenomenon of the subjects' multiplication of law and regulatory sources internationally. Finally, scrutinize the issue of recognition of the post-national legal sources constructed by autonomous private actors in relation to state action. We conclude that, due to the confluence of rules, whether public, whether private, even if derived from internal markedly or even extra-legal phenomena, in today's post-national context, is impossible to speak exclusively in a public and in a private international law, because legal domains; (for example, lex mercatoria, lex financeira, lex eletronica, lex desportiva, among 
others); reveal normative sets produced by leading global private companies focused on achieving "public interests". However, the mere autonomy of the "social contacts" is insufficient to generate legally binding commitments, then, without unity, fragmented legal expressions have lukewarm bonds. Therefore, this study is endowed with originality and merely relevant to the structure of post-national legal frame, specifically, the private nature of the entities and rules of international law in a scenario of internationalisation of law. Without pretensions to exhaust the subject, the work focuses, among others, the differences in the formation and implementation of post-national law and state law.

Keywords: State law. Law of conflits. Post-national law. Private entities. Internationalisation of law.

\section{Introdução}

O direito internacional apresenta-se, hoje, mais denso e complexo em virtude da multiplicação da quantidade de sujeitos de direito internacional e do aumento do número de normas, fruto tanto de um processo de autolimitação imposto pelo ente estatal a si mesmo, quanto de um processo autônomo em cuja gênese encontram-se manifestações infraestatais públicas e privadas. Deste último e intrigante fenômeno, as reflexões apresentadas nesse estudo tratam, particularmente, da produção normativa pósnacional legítima e efetiva, conquanto independente do Estado e realizada por entes transnacionais privados.

Em relação à perda do poder estatal exclusivo de produção normativa, ou seja, que o Estado participe dessa produção em igualdade com atores privados transnacionais, surgem novos desafios para a teoria dos sujeitos do direito internacional. A partir da concepção positivista contemporânea, o problema está no fato de que normas puramente privadas não compõem o direito positivo, em virtude das múltiplas normas de validação remetendo a fundamentos de validade diferentes, e da lógica heterárquica e policêntrica de produção e controle normativo. Em outras palavras, a viabilidade dessas manifestações jurídicas encontra barreiras na natureza de seus sujeitos e normas, na impossibilidade de normas privadas se autovalidarem ou, ainda, na incapacidade de mecanismos jurídicos particulares vincularem entes estatais.

A lógica de Kelsen propugna tanto a validade formal das normas, quanto a de Hart, a regra de reconhecimento, o que impede legitimar juridicamente redes transnacionais, à luz do positivismo clássico, salvo caso se aceite a existência de uma pluralidade de normas hipotéticas fundamentais ou de regras de validação. Todavia, não se deve olvidar que, para alguns autores, fontes normativas privadas já se apresentam atualmente em número e importância maior do que as fontes tradicionais do direito internacional, figurando, assim, no centro do sistema.

Em distintos sistemas jurídicos, a exemplo da lex eletronica, da lex desportiva, da lex financeira e da lex mercatoria, conflitos são solucionados mediante normas próprias de conduta e processos de negociação entre os atores, ferramentas de sanção, cuja efetividade é própria de cada sistema, o conceito de obrigatoriedade é substituído pelo de "níveis de obrigatoriedade", e agentes econômicos impõem globalmente seus interesses particulares. Isso produziu, no contexto pósmoderno, a "privatização do direito internacional", ou seja, um quadro de sujeitos e normas não somente mais numerosos, mas também mais participativos.

Nesse cenário, exsurgem algumas dúvidas: é possível classificar normas pós-nacionais como novas fontes do direito internacional? Em caso afirmativo, quais e quantas normas infraestatais comuns entre dois Estados são necessárias? Quais e quantos atos de entidades particulares em redes transnacionais são necessários? E sob qual critério? Dentre os novos sujeitos, existe um responsável pela condução do novo sistema? É possível delinear os limites do direito pós-nacional? O certo é que essa nova realidade em formação oriunda de novas formas de interação entre os atores transnacionais somente pode ser entendida sob a ótica da internacionalização do direito. Portanto, faz mais sentido pensar em um conjunto denso de soft norms, que emoldura de maneira peculiar um direito pós-nacional, do que em novos sujeitos e fontes do direito internacional imponíveis, inclusive, aos Estados nacionais.

\section{A teoria das fontes do direito no contexto pós-nacional}

A expressão "fonte do direito" significa "onde está o direito", de forma figurativa, como uma nascente d'água designa sua procedência. Procurar onde está o Direito é buscar o local onde ele foi revelado e o que lhe faz legítimo, isto é, seus fundamentos de obrigatoriedade - vigência e eficácia. Dessa maneira, no plano internacional, a teoria das fontes do direito almeja justificar a obrigatoriedade de certas regras aos sujeitos do direito internacional. ${ }^{1}$

1 Tratamos desse assunto de forma mais aprofundada no 
As fontes do direito internacional são compreendidas dentro da lógica de interdependência entre os Estados para a vida em comunidade, da justiça social, do consentimento ou de interesses. Trata-se de uma visão antropomórfica do Estado, que o compara a uma sociedade de indivíduos com igualdade e liberdade. ${ }^{2}$ No século XX, sobretudo a partir dos trabalhos de Kelsen e Hart, o positivismo jurídico consolidou-se como principal teoria explicativa das fontes de direito internacional.

Para Kelsen, o caráter de fonte de direito implica o fundamento de validade formal, independentemente dos elementos materiais da norma. Dessa maneira, há sempre uma norma hierárquica superior que prevê uma inferior. De um mero decreto, passando por uma lei, infraconstitucional e depois constitucional, até se chegar à norma hipotética fundamental, que dá validade a todo o ordenamento jurídico.

Kelsen, ao elaborar a "Teoria Pura do Direito" e construir a pirâmide de normas, enunciou que a origem e a obrigatoriedade de uma norma encontramse naquela imediatamente superior. No vértice da pirâmide repousa a norma fundamental ou norma base (Grundnorm). Primeiramente, essa concepção foi chamada de Teoria da Livre Escolha. Posteriormente, com a influência de Verdross, Kelsen abandona seu indiferentismo e define a Grundnorm como sendo uma norma de direito internacional, a norma costumeira pacta sunt servanda ${ }^{3}$

Tendo como ponto de partida a validade do Direito Internacional, surge a questão de saber como se poderá fundamentar a validade da ordem jurídica estadual; e, nessa hipótese, esse fundamento de validade tem de ser encontrado na ordem jurídica internacional. Isso é possível porque o princípio da efetividade, que é uma norma do Direito Internacional positivo, determina, tanto o fundamento de validade, quanto o domínio territorial, pessoal e temporal de validade das ordens jurídicas estaduais, e estas, por conseguinte, podem ser

texto: ELIAS, Fernando Lopes Ferraz. Fontes do direito: o direito internacional como a grande norma kelseniana. In: CONGRESSO BRASILEIRO DE DIREITO INTERNACIONAL., 7., 2009, Curitiba. Anais...Curitiba: Juruá, 2009. v. 17. p. 227-237.

2 VARELLA, Marcelo Dias. Internacionalização do direito: direito internacional globalização e complexidade. 2012. 606 f. Dissertação (Tese de Livre-docência) -- Faculdade de Direito, Universidade de São Paulo, São Paulo, 2012. f. 437- 439.

3 MELLO, Celso Duvivier de Albuquerque. Curso de direito internacional público. 12. ed. Rio de Janeiro: Renovar, 2000. v. 1. p. 112. concebidas como delegadas pelo Direito Internacional, como subordinadas a este, portanto, e como ordens jurídicas parciais incluídas nele como numa ordem universal, sendo a coexistência no espaço e a sucessão no tempo de tais ordens tornadas juridicamente possíveis somente por meio do Direito Internacional. Isso significa o primado da ordem jurídica internacional. ${ }^{4}$ É especialmente interessante o raciocínio kelseniano de que as ordens jurídicas nacionais encontram seu fundamento de validade no direito internacional, cuja norma hipotética fundamental, a seu turno, está fundada nos costumes dos Estados. Dessa maneira, as normas de direito internacional são definidas como o fundamento de validade do direito interno.

Kelsen retira o elemento volitivo de todas as etapas da construção do direito, identificando uma realidade. Trata-se de uma teoria objetiva, que não reconhece o Estado como um ente capaz de expressar vontade própria, mas uma ordem jurídica que atribui a determinados indivíduos a indicação da vontade daquela comunidade. Os costumes internacionais, para Kelsen, são depreendidos da análise objetiva da realidade, ou seja, os Estados cumprem esses costumes, porque sempre cumpriram, considerando-os como direito aplicável. ${ }^{5}$

O desvanecimento da diferenciação entre direito internacional e direito interno é consequência de um processo de evolução técnico-jurídica, que culmina no perfazimento de um único sistema normativo e uma comunidade universal. ${ }^{6}$ Pautado nessa visão kelseniana, pode-se destacar o recente processo de internacionalização da vida jurídica, não existindo assunto ou matéria invulnerável a ser internacionalizado. ${ }^{7}$ Em outras palavras, o intercâmbio comercial internacional reflete o momento histórico atual de integração e interdependência dos Estados. No profético discurso de Kant: "[...] é o espírito comercial, que mais cedo ou mais tarde se apodera de cada povo". ${ }^{8}$

$4{ }^{5}$ KELSEN, Hans. Teoria pura do direito. Tradução: João Baptista Machado. 6. ed. São Paulo: Martins Fontes, 1998. p. 374.

5 VARELLA, Marcelo Dias. Internacionalização do direito: direito internacional. globalização e complexidade. 2012. 606 f. Dissertação (Tese de Livre-docência) -- Faculdade de Direito, Universidade de São Paulo, São Paulo. f. 442.

6 ELSEN, Hans. Teoria pura do direito. Tradução: João Baptista Machado. 6. ed. São Paulo: Martins Fontes, 1998, p. 364.

7 MELLO, Celso Duvivier de Albuquerque. Curso de direito internacional público. 12. ed. Rio de Janeiro: Renovar, 2000. v. 1. p. 113.

8 KANT, Imannuel. A paz perpétua. Tradução Marco A. Zingano. Porto Alegre: L\&PM, 1989. p. 55. 
Para os fins colimados por esta pesquisa, cumpre destacar que a lógica kelseniana conhece apenas o direito estatal. As normas privadas, como contratos, podem integrar o ordenamento jurídico a título de normas individuais. Não há uma necessária contraposição entre um "direito estatal" e um "direito não estatal", se o primeiro admite o segundo como norma válida. No entanto, este não vale para direitos privados criados independentemente da ordem jurídica estatal, porque eles não têm o mesmo elemento de validade formal exigido para a identificação de qualquer norma, como parte do ordenamento jurídico. Para Kelsen, a relação entre os atores privados e o sistema jurídico na formulação e controle de regras estaria no plano não jurídico ou sociológico. ${ }^{9}$

Todavia, o crescimento da influência de um direito privado conduz a um cenário onde as regras privadas podem inclusive independer das regras públicas para serem válidas. $E$, principalmente, o direito não estatal pode tanto reforçar, como ignorar, ou até mesmo contrariar o direito estatal. A relação entre esses regimes normativos autônomos e o direito produzido pelo Estado pode ser de colaboração, de indiferença, ou, ainda, de oposição. O direito é construído por elos formais ou informais em redes de atores privados com interesses variados com, sem ou contra a vontade dos Estados nacionais..$^{10}$

Hart, por sua vez, acrescenta à validade formal a complexidade da regra de reconhecimento, isto é, a norma positiva precisa ser reconhecida como tal pelos operadores jurídicos mais importantes - juízes e agentes públicos - para ser considerada válida. Ao reconhecer uma norma, esses tomadores de decisão escolhem a norma de validade. Assim, Hart coloca as práticas sociais no centro de sua teoria. ${ }^{11}$

No contexto pós-nacional, consoante as ideias de Hart, há uma situação anormal, capaz de corroer todo o sistema jurídico, haja vista que os atores reconhecem diferentes regras de validação, distintas e antagônicas entre si e, às vezes, até interconectadas. Além disso,

9 VARELLA, Marcelo Dias. Internacionalização do direito: direito internacional. globalização e complexidade. 2012. 606 f. Dissertação (Tese de Livre-docência) -- Faculdade de Direito, Universidade de São Paulo, São Paulo. f. 459.

10 VARELLA, Marcelo Dias. Internacionalização do direito: direito internacional, globalização e complexidade. 2012. 606 f. Dissertação (Tese de Livre-docência) -- Faculdade de Direito, Universidade de São Paulo, São Paulo. f. 294-459.

11 HART, H. O conceito de direito. 3. ed. Lisboa: Fundação Calouste Gulbenkian, 1994. p. 121. o peso de cada fonte ou norma depende do tema e não apenas de sua origem, bem como de cada ator envolvido, em diferentes esferas. ${ }^{12}$

Dessa forma, a dificuldade em aceitar essas novas manifestações normativas estaria em atribuir ao sistema jurídico uma multiplicidade de fundamentos de validade, determinados por diversas variações na regra de reconhecimento. É possível afirmar que o fundamento das fontes sempre esteve calcado sejam em razões jusnaturalistas, sejam em razões positivistas, ou, ainda, numa combinação entre ambas.

De alguma maneira, jusnaturalismo e positivismo precisam um do outro. O jusnaturalismo necessita de argumentos positivistas para justificar de maneira objetiva o comprometimento dos Estados com conteúdos vagos como justiça, interesse comum e razoabilidade. O positivismonecessita do jusnaturalismo para esclarecer, a partir de comportamentos, vontades e interesses, por que obrigações são imperativas. Além disso, visões excludentes de cada uma dessas linhas teóricas conduzem a consideráveis dificuldades. O caráter obrigatório de um pacto resta igualmente comprometido se, de uma parte, os Estados puderem, quando e como melhor lhes aprouver, retirarem-se de um tratado, e, de outra, caso não puderem jamais alterar seus consentimentos. Dessa forma, ficariam sem sentido, por um lado, ideias como as de jus cogens, costumes obrigatórios a novos Estados, e, por outro, as de pacta sunt servanda, entre tantos outros institutos basilares do direito internacional. ${ }^{13}$

Para se considerar as novas manifestações como normas jurídicas, é preciso sair do positivismo jurídico. Conforme Kelsen, não importa se, do ponto de vista material, manifestações jurídicas regulam a vida dos Estados e dos indivíduos. Os atores subestatais - gestores públicos e juízes - ou privados não têm autoridade formal dos Estados para produzir normas juridicamente obrigatórias. Em Hart, ainda que se admita um processo dinâmico, não se aceita a multiplicidade das normas de validação. Nesse ponto repousa o principal problema do uso das ideias positivistas contemporâneas para explicar a proliferação de normas: as novas manifestações normativas, produzidas por agentes subestatais e transnacionais, públicos e privados têm

12 KRISCH, Nico. Beyond constitucionalism: the pluralism structure of posnational law. Oxford: Oxford University Press, 2010.p. 12.

13 KOSKENNIEMI, Martti. From apology to utopia: the structure of international legal argument, reissue with a new epilogue. Cambridge: Cambridge University, 2005.p. 304-310. 
diferentes fontes de validação. Apenas podem ser entendidas se aceitarmos a ideia de uma multiplicidade de normas hipotéticas fundamentais ou de regras de validação, além do Estado, o que não foi previsto por Kelsen, tampouco por Hart. ${ }^{14}$

Contudo, não é necessário abandonar o positivismo jurídico, porquanto continua a existir para um determinado núcleo ainda central de normas jurídicas, mas coexiste com outras lógicas que não consegue explicar. Os Estados continuam a ser elementos nucleares na coordenação entre as ordens jurídicas nacionais, mas outras redes transnacionais ganham importância. Ainda que não se considere como suficiente para produzir novas normas à luz do positivismo tradicional, os discursos normativos setoriais, cada vez mais transnacionais, contribuem para alterar como os atores entendem os significados das normas jurídicas. Podemos chamar o novo cenário de pós-positivista ou pós-modernista, o que varia conforme os autores. ${ }^{15}$

Entre os autores do final do século XX e início do século XXI, há diversas posições, desde aqueles que entendem a maior complexidade do direito internacional a partir das teorias tradicionais, sejam dos autores modernos, sejam dos clássicos do século XX, principalmente no positivismo, até os que identificam pluralismo de fontes e atores dentro de uma ideia de contradição entre subsistemas jurídicos, em que a fragmentação seria a expressão de múltiplas normas de validação. Assim, a aceitação das novas normas privadas como verdadeiras fontes do direito internacional varia de um caso a outro.

Os autores mais recentes que explicam a nova complexidade no direito internacional dentro da teoria tradicional do direito, marcada pelos argumentos de validade da norma jurídica internacional, desde o século XVIII, consoante os interesses e valores de cada época, apontam que, hoje, a legitimidade das fontes, ou seja, a obrigatoriedade do vínculo jurídico seria melhor entendida pelo consentimento tácito do que pelo expresso, o que permitiria confluência, ao invés de críticas mútuas, entre os fundamentos de validade

14 VARELLA, Marcelo Dias. Internacionalização do direito: direito internacional, globalização e complexidade. 2012. 606 f. Dissertação (Tese de Livre-docência) -- Faculdade de Direito, Universidade de São Paulo, São Paulo. f. 442-443.

15 VARELLA, Marcelo Dias. Internacionalização do direito: direito internacional, globalização e complexidade. 2012. 606 f. Dissertação (Tese de Livre-docência) -- Faculdade de Direito, Universidade de São Paulo, São Paulo. f. 296, 443,464. tanto da corrente jusnaturalista quanto da positivista, a exemplo da regra rebus sic stantibus, pertinente à alteração do pacto devido a mudanças sociais posteriores. Dessa forma, o fundamento não repousa exclusivamente sobre padrões normativos ou puramente morais, senão sobre algo que envolveria ambos, nomeado de "conceito social do direito".

O direito é criado de uma forma ascendente, por meio de comportamentos, vontades e interesses dos Estados, mas também descendente, com base em valores preexistentes. A real concepção do direito significa pelo menos manter uma distância marginal entre o direito e a realidade social. ${ }^{16}$

O problema é que, a partir desse ponto, o autor desconsidera as racionalidades próprias de cada setor e afirma que conflitos normativos do direito internacional, independentemente de serem relativos a questões humanas, ambientais ou comerciais, por exemplo, podem ser resolvidos dentro do caso concreto, a partir do uso de regras de lex specialis e lex generalis. A fim de garantir a indispensável discricionariedade à aplicação da justiça, os casos deveriam ser interpretados pelos operadores jurídicos.

Ademais, o autor é incapaz de definir, sem confundir com meras questões políticas, o comportamento e a visão de justiça de quais Estados devem ser considerados para determinar esse direito e como justificar a escolha. O uso do direito como uma linguagem perde em parte a racionalidade e os limites de validade jurídica para transformar-se em manifestação política. O problema torna-se complexo, porque os seres humanos convivem paralelamente em diferentes sistemas jurídicos. Assim, um indivíduo utiliza o sistema jurídico estatal durante diferentes atividades quotidianas, a lex eletronica quando checa seus e-mails, a lex desportiva quando participa de um jogo de futebol ou assiste a um. As sociedades passam de um regime a outro rotineiramente, no mesmo espaço, no mesmo tempo. As regras de especificidade e generalidade mais uma vez não funcionam, porque aqui as normas privadas sequer seriam julgadas parte do ordenamento jurídico, de acordo com as regras. ${ }^{17}$

16 KOSKENNIEMI, Martti. From apology to utopia: the structure of international legal argument, reissue with a new epilogue. Cambridge: Cambridge University, 2005, p. 333, 337, 344, 385.

17 VARELLA, Marcelo Dias. Internacionalização do direito: direito internacional, globalização e complexidade. 2012. 606 f. Dissertação (Tese de Livre-docência) -- Faculdade de Direito, Universidade de São Paulo, São Paulo f. 445, 462- 463. 
Ademais, em subsistemas privados, como a lex mercatoria, o justo pode ser muito diferente para a lógica do direito ambiental ou outro, por exemplo. A solução é limitada quando a norma especial não contrapõe de forma expressa a norma geral e envolve as mesmas partes. Um instrumento pode ainda ser geral para um órgão e especial para outro, enquanto o mesmo problema pode muitas vezes ser discutido em ambos. Portanto, é limitado desconsiderar peculiaridades e concepções diferentes de justiça. Num cenário de heterarquia entre os sistemas normativos, sem regras prévias de solução de antinomias, além da aplicação de regras específicas pelos juízes, os conflitos são comumente resolvidos por processos de negociação entre os diferentes regimes, com a busca de pontes de diálogo entre os atores, criando interpretações jurídicas comuns ou mantendo os antagonismos. ${ }^{18}$

Nesse sentido, numerosas fontes internacionais - até mesmo declaratórias - são frequentemente citadas por órgãos de solução de conflitos internacionais. Contudo, pela análise de casos concretos, observa-se que o instrumento externo, ainda que mais específico, não é um fim em si mesmo e, portanto, não há relação direta dele com a interpretação feita pelo órgão de controle. Essas ideias são ilustradas, entre outros tantos, com os seguintes contenciosos. ${ }^{19}$

No caso Leyla Sahin v. Turquia, 2005, a respeito da proibição de acesso à universidade turca de uma estudante muçulmana trajando o véu vis-ăvis a restrição do porte de símbolos religiosos em instituições de ensino. No \136, a Corte Europeia de Direitos Humanos invocou a Recomendação 1353 (1998), específica sobre acesso de minorias ao ensino superior e a Recomendação (98)3 sobre o acesso ao ensino superior, importante para a promoção dos direitos do homem e das liberdades públicas e para o fortalecimento da democracia, todavia, decidiu que o acesso à universidade dependia da adequação às normas sobre vestimentas.

No contencioso Bancovic e outros v. Bélgica, 2001, para determinar a noção de jurisdição na Corte Europeia de Direitos Humanos. Nos $\iint 75$ - 78, os argumentos invocados pelos requerentes calcados nas Convenções de Genebra, de 1949; na Declaração

18 TEUBNER, G. Constitutional fragments. Oxford: OUP, 2012. p. 153.

19 TURGIS, Sandrine. Les Interactions entre les norme internationales relatives aux droits de la personne. Paris: Editions A. Pedone, 2010. p. 317-318.
Americana de Direitos do Homem; na Convenção Americana de Direitos e Deveres do Homem; nas decisões da Comissão Interamericana de Direitos Humanos e no Pacto Internacional de Direitos Civis e Políticos; foram rejeitados, pois a noção de jurisdição, segundo a Corte Europeia de Direitos Humanos, não é semelhante às daquelas Convenções, porque assim não quiseram os autores da Convenção Europeia de Direitos Humanos.

No caso Soering $v$. Reino Unido, 1989, acerca da extradição de um indivíduo para os Estados Unidos e sua consequente execução à pena de morte. No $\int 86$, a Corte Europeia de Direitos Humanos ressaltou as diferenças entre a Convenção Europeia de Direitos Humanos e os instrumentos internacionais citados na defesa daquele governo, quais sejam, a Convenção relativa ao status dos refugiados, a Convenção Europeia de extradição e a Convenção da ONU contra a tortura e impingiu ao juiz criminal o dever de verificar se há compatibilidade entre os direitos penais de ambos Estados, com base no art. $3^{\circ}$. da Convenção Europeia de Direitos Humanos, que proscreve o tratamento desumano e degradante, por estimar o tempo de espera no corredor da morte, particularmente no Estado da Virgínia, abusivo e cruel para o condenado. Ademais, no $\int 108$, a Corte Europeia de Direitos Humanos destacou que diferente da redação concisa e geral do art. $2^{\circ}$. da Convenção Europeia de Direitos Humanos, os instrumentos internacionais que lhe são posteriores - a Convenção Americana de Direitos Humanos e o Pacto Internacional de Direitos Políticos e Civis proíbem expressamente a pena capital a menores de dezoito anos.

Finalmente, os autores que reconhecem a existência e proliferação de fontes normativas privadas afirmam que, hoje, o volume de manifestações jurídicas por redes de atores é tão grande e relevante que já superaria em quantidade e importância as tradicionais fontes do direito internacional público. Não se tratam de normas periféricas, ao contrário, ocupam a centralidade do sistema. Portanto, o direito internacional seria edificado, principalmente, por manifestações normativas oriundas de redes normativas privadas e subestatais, neste caso, com destaque para o papel dos juízes. ${ }^{20}$

Se com a multiplicação de tribunais internacionais cresce a possibilidade de decisões contrárias, isso

20 TEUBNER, G. Global law without a state. Hants: Dartmouth, 1997. 
aumenta e não diminui o papel do direito internacional, faz do direito internacional algo mais relevante do que era antes. O ritmo com que leis e instituições internacionais são criadas é um confiável indicador da força e da importância do direito internacional e que os problemas associados à fragmentação representam pouco mais do que custos transitórios de ajuste. $\mathrm{O}$ risco de fragmentação pode ser minimizado pelo aumento do diálogo entre juízes, responsável por importantes implicações para a unidade da ordem jurídica internacional, na medida em que eles se comunicam, compartilham informações e, quando possível, resolvem conflitos potenciais antes mesmo de eles ocorrerem. ${ }^{21}$

A pluralidade de nós autônomos das redes possibilita que o mundo seja observado de diferentes perspectivas, mas também podem ser transformados numa rede de decisões. A multiplicidade de perspectivas substitui o tradicional modelo racionalista obcecado pela uniformidade. O papel das Cortes nas redes não é o de regenerar uma incerteza em outra, mas a pluralidade de observações e posições diferentes. Se elas forem capazes de reunir essas perspectivas numa consistente rede de decisões, provocaram o que há de mais valioso no poder de julgar: diante da colisão de universos significativos diferentes, decidir por que a decisão se faz necessária. ${ }^{22}$

\section{0 fenômeno da multiplicação de sujeitos de direito e de fontes normativas no plano internacional}

A proliferação de sujeitos e normas de direito internacional, ambos movimentos simultâneos e interligados, concretiza-se, hodiernamente, por duas maneiras: (i) aumento do número de instrumentos normativos tradicionais de direito internacional público - tratados, costumes, princípios gerais do direito internacional e atos unilaterais - decorrente da multiplicação do número de Estados, com o processo de descolonização da África e da Ásia e da dissolução da maioria dos Estados socialistas, bem como do crescimento da quantidade de Organizações Internacionais; (ii) surgimento de fontes jurídicas

21 BURKE-WHITE, W., International legal pluralism. Michigan Journal of International Law, v. 25, p. 963- 979, 2004.

22 TEUBNER, G. And if i by beelzebub cast out devils: an essay on the diabolics of network failure. German Law Journal, v. 10, n. 4, p. 115-136, 2009. p. 136. edificadas por redes de atores infraestatais públicos e privados.

$\mathrm{Na}$ seara da primeira maneira, constata-se um expediente atual de delegação da capacidade de criação normativa internacional do Estado-nação portanto, um ato de soberania do próprio Estado - para Organizações Internacionais, em virtude da expansão do direito internacional sobre temas antes de domínio exclusivamente interno. Ademais, observase a ampliação de normas comuns nacionais, isto é, normas de direito doméstico que tutelam questões com repercussões internacionais, como proteção sanitária e ambiental, regulação de mercados, combate ao terrorismo, à corrupção e à lavagem de dinheiro; entre tantas outras.

Grosso modo, essas normas produzidas por Organizações Internacionais, apresentam características peculiares que lhes permitem serem classificadas em razão de seu caráter vinculante, em obrigatórias e não obrigatórias; ao passo que as normas construídas por Estados podem ser catalogadas em virtude de sua diversidade, consoante o alcance seja nacional, regional ou internacional. Todavia, o problema continua em como avaliar as novas manifestações normativas em razão dessas chaves classificatórias.

Em tratados considerados softs norms, base de alguns subsistemas jurídicos, há possibilidade de cumprimento parcial por determinados Estados, em razão dos conceitos de margem nacional de apreciação e níveis aceitáveis de risco que possibilitam interpretações distintas (direitos distintos) à luz de um mesmo texto normativo. A teoria das fontes ganha variações de cores mais acentuadas na contemporaneidade, quando se concebe fonte não como uma norma obrigatória, mas como aquela que admite níveis de obrigatoriedade e de diversidade. ${ }^{23}$

O direito internacional pós-moderno reflete a complexidade e a diversidade do mundo sobre o qual atua, afirmando, por um lado, obrigações erga omnes, a exemplo de Pareceres da Corte Internacional de Justiça ou de Resoluções do Instituto de Direito Internacional; por outro, a diversidade e flexibilidade de mecanismos

23 VARELLA, Marcelo Dias. Internacionalização do direito: direito internacional, globalização e complexidade. 2012. 606 f. Dissertação (Tese de Livre-docência) -- Faculdade de Direito, Universidade de São Paulo, São Paulo. f. 448. 
não vinculantes, como soft law, não obstante as resistências que possa suscitar. ${ }^{24}$

Por sua vez, quanto à segunda maneira, cumpre observar que não há direito sem fonte, em verdade, o direito se realiza em suas fontes normativas. Do mesmo modo, não há que se falar em direito pós-nacional sem se considerar duas manifestações normativas infraestatais: (i) as públicas - como os processos de confluência normativa, construção de uma gramática comum, fertilização cruzada, normas produzidas por agentes públicos, entre outras - e, (ii) as privadas - contratos, principalmente em redes de empresas, lex mercatoria, lex financeira, lex eletronica, lex desportiva, dentre outras - , ou seja, independentes da ordem jurídica estatal.

A respeito da ação de atores subestatais públicos, decisões de juízes nacionais ou gestores públicos são fatos jurídicos e não fontes de direito internacional. Todavia, conquanto seja necessário distinguir um compromisso assumido pelo Estado no plano internacional da maneira como ele será interpretado e aplicado internamente por funcionários públicos, é responsabilidade do Estado zelar pelo cumprimento interno das obrigações jurídicas que assume internacionalmente.

A realidade fragmentada de posições dentro de um mesmo Estado, característica da expansão de manifestações normativas transnacionais, dificulta a construção de posições comuns, na realidade, sequer reflete a posição pacífica ou mesmo dominante em um Estado. Destarte, pode ser que alguns juízes ou gestores atuem de determinada forma, em parceria com seus colegas em outros Estados, participando da construção de um discurso normativo setorial, mas que os demais atores equivalentes (outros juízes nacionais ou outros gestores) discordem e não apliquem os mesmos conceitos. Assim, diante do fato de o Estado não ser um bloco monolítico de poder, a solução para encontrar pontes de relacionamento entre a ideia tradicional de fontes de direito e manifestações internas nos Estados, pelo direito internacional de hoje, é avaliar a importância dessas manifestações como suficiente para indicar a posição de fato do Estado em relação a uma situação concreta. ${ }^{25}$

24 ACCIOLY, Hildebrando; SILVA, Geraldo Eulálio do Nascimento; CASELLA, Paulo Borba. Manual de direito internacional público. 16. ed. São Paulo: Saraiva, 2008. p. 759-760.

25 VARELLA, Marcelo Dias. Internacionalização do direito: direito internacional, globalização e complexidade. 2012. 606 f. Dissertação (Tese de Livre-docência) -- Faculdade de Direito, Universidade de
Dentre essas mudanças estruturais diretamente impostas pela globalização, surgem algumas que também vão afetar diretamente a concepção tradicional do Direito, sendo possível apontar diversas tendências, dentre as quais merece especial destaque uma mudança na forma de produção de direito. Especificamente no que tange à produção normativa, a perda do protagonismo estatal de produção normativa leva indubitavelmente a um fenômeno de internacionalização do direito. $\mathrm{O}$ direito não vem mais apenas do Estado, mas também de organizações supranacionais, de outros Estados ou até mesmo de agentes privados, dessa forma, o Estado vem perdendo sua centralidade na atual configuração do mundo. Diante dessa situação, impõe-se o surgimento de novos atores que assumirão o papel de protagonistas inclusive na produção de normas jurídicas. Nesse particular, os agentes econômicos têm poder suficiente para fazer valer seus interesses em escala global. ${ }^{26}$

O fenômeno da internacionalização do direito a partir de diferentes fenômenos privados de construção normativa pode ser analisado a partir de três modelos, conforme os novos regimes jurídicos privados sejam construídos em relações de maior ou menor dependência, ou mesmo de forma paralela, aos regimes jurídicos estatais.

No primeiro, conforme a teoria positivista tradicional, as normas privadas foram previstas pelo direito estatal, como os contratos bilaterais, por exemplo, no exercício da autonomia privada. Existem em função dessa previsão e dependem dos Estados para serem efetivas, a exemplo da necessidade de se recorrer a tribunais nacionais para se executar um contrato que tenha sido desrespeitado ou mesmo uma decisão de um órgão arbitral internacional. Nesse modelo, a proliferação de normas privadas não afeta a centralidade do Estado, mas apenas contribui para o deslocamento do eixo público de produção normativa para um eixo privado, mas sempre com legitimidade no próprio Estado nacional que autorizou ambos os processos. $^{27}$

São Paulo, São Paulo. f. 451.

26 TOMAZETTE, Marlon. Internacionalização do direito além do Estado: a nova lex mercatoria e sua aplicação. Revista de Direito Internacional. Brasília, v. 9, n. 4, p. 93-123, 2012. p. 94-118

27 VARELLA, Marcelo Dias. Internacionalização do direito: direito internacional, globalização e complexidade. 2012. 606 f. Dissertação (Tese de Livre-docência) -- Faculdade de Direito, Universidade de São Paulo, São Paulo. f. 297, 436, 459. 
O direito construído por entes privados se amolda ao paradigma jurídico clássico, e o poder normativo privado pertence à lógica hierárquica estatal preestabelecida, portanto, não há perda do monopólio por parte do Estado. Nesse modelo, a efetividade do direito internacional depende das autoridades judiciárias nacionais. Não há que se falar em autonomia do ordenamento privado em relação à lógica da tradicional visão piramidal do direito. ${ }^{28}$

No segundo, o Estado, confrontado por diversos subsistemas jurídicos, aceita seus limites e abdica de posturas intervencionistas e controladoras, atribuindo a distintos setores privados capacidade de autogestão, que se autofiscalizam mediante instrumentos próprios. $^{29}$ Uma maior autonomia privada convive com a participação do Estado, conquanto esteja esta limitada a delinear somente alguns objetivos gerais ao setor privado, renunciando ao método de comando e controle, ao reconhecer a existência de subsistemas cada vez mais distintos do sistema estatal (economia, mercados financeiros, saúde pública, entre outros). A legitimidade do direito é conferida pelos atores envolvidos, a um só tempo, produtores e destinatários dessas normas. ${ }^{30}$

No terceiro, há a proliferação de mecanismos criados pelas próprias redes de atores privados autônomos em relação aos Estados, verdadeiro "direito sem Estado". O Estado não participa da relação jurídica, não a legitima, e o direito independe do Estado para se tornar efetivo. Esse direito não encontra o mesmo fundamento de validade formal da norma estatal. Nesse modelo os regimes privados possuem formas de sanções praticadas por redes de atores, cuja efetividade independe da soberania estatal e do direito hierarquizado imposto pelo Estado, mas da autonomia das relações heterárquicas entre múltiplos atores privados e racionalidades sem coordenação. ${ }^{31}$

28 OST, F; KERCHOVE. De la pyramide an reseau: pour une théorie dialectique du droit. Bruxelles: Públications des Facultés Universitaires Saint-Louis, 2002. p. 75-76.

29 OST, F; KERCHOVE. De la pyramide au reseau: pour une théorie dialectique du droit. Bruxelles: Públications des Facultés Universitaires Saint-Louis, 2002. p. 76.

30 TEUBNER, G. Droit et réflexivité: l'auto-référence en droit et dans l'organisation. Tradução de N. Boucquey. Paris-Bruxelles: Story-LGDJ, 1994.

31 TEUBNER, G. Les multiples corps du roi: l'auto-destruction de la hiérarchie du droit, In: Philosophie du droit et droit économique, quel dialogue? Paris: Frison-Roche, 1999. p. 312-313.
A equivalência entre ordens normativas, públicas ou privadas, entre diferentes Estados, denota a expansão do universo jurídico das fontes do direito internacional ao incluir fenômenos considerados tipicamente internos ou extrajurídicos. Assim, o direito internacional (nem meramente público, nem privado) incluiria todas as normas transnacionais. A propósito, são chamados de regimes privados, porque suas normas são formuladas, implementadas e julgadas por atores de igual nível hierárquico, sejam privados ou públicos. ${ }^{32}$

Há uma tríplice ameaça ao modelo jurídico clássico. A produção hierárquica cede espaço a iniciativas heterárquicas, a soberania do Estado central, à autonomia de subsistemas cada vez mais expansivos, enquanto a racionalidade do conjunto cederia seu lugar a uma multiplicidade de lógicas setoriais pouco coordenadas. ${ }^{33} \mathrm{O}$ Estado-fonte de normas sofre o processo de descentralização de fontes; o Estado-esfera pública sofre a privatização e, especificamente, o Estadonação é ameaçado pela internacionalização do direito, cujos valores globais lhe impingem transformações não apenas externas, mas também internas. ${ }^{34}$

Ainda sobre sistemas jurídicos privados com pretensão de autonomia, não se trata de uma recorrente crítica ao positivismo jurídico, são desenvolvimentos históricos na prática do direito que agora rompem com uma estrutura tradicional. Esse grande paradoxo não atende pelo nome de Jacques Derrida ou de Niklas Luhmann, senão da própria globalização! Os Estados-nação já não podem mais silenciar as dúvidas sobre o positivismo hierárquico, que emergem com o caráter apátrida da lex mercatoria, dentre outros direitos globais. É a globalização do direito responsável pelo fim da soberania e pela visibilidade desse paradoxo. ${ }^{35}$ Assim, grupos não-governamentais, movimentos sociais, organizações profissionais, igrejas, federações esportivas, organizações humanitárias ou ambientais, dentre outras tantas, impõem regras próprias que,

32 VARELLA, Marcelo Dias. Internacionalização do direito: direito internacional, globalização e complexidade. 2012. 606 f. Dissertação (Tese de Livre-docência) -- Faculdade de Direito, Universidade de São Paulo, São Paulo. f. 297, 450.

33 OST, F; KERCHOVE. De la pyramide au reseau: pour une théorie dialectique du droit. Bruxelles: Públications des Facultés Universitaires Saint-Louis, 2002. p. 77.

34 DELMAS-MARTY, M. Les forces imaginantes du droit: le pluralisme ordonné. Paris: Seuil, 2005. v.2

35 TEUBNER, G. The king's many bodies: the selfdescontruction of law's hierarchy. Law and Society Review, v. 31, n. 4, p. 763-787, 1997, p. 768-769. 
em muitos casos, atingem mais pessoas, envolvem mais recursos e têm mais efetividade do que as regras estatais. $^{36}$

Há uma interação bastante próxima de conjuntos normativos promovidos por empresas privadas que atuam em âmbito global. Devido ao aumento da importância dessas empresas e cadeias produtivas, passam a ter relevância na consecução de "objetivos públicos". Existem vários motivos para tanto: pressões de mercados consumidores não apenas em seu país de origem, como nos mercados globais; pressões de organizações não governamentais e outros atores cívicos por determinados padrões de consumo de grupos setoriais; necessidade de atender a determinados padrões para obter certificações em processos de normalização, como a ISO 14000 em relação ao meio ambiente, ou a ISO 19000 em relação a normas trabalhistas; construção de políticas institucionais em consonância com valores emergentes, como a proteção dos direitos humanos, a não exploração do trabalho infantil, o respeito por orientações sexuais, a liberdade de expressão, a igualdade de gênero e raça, entre tantos outros valores emergentes. ${ }^{37}$

Nessa esteira, pode-se ainda destacar, a título de exemplo, diferentes selos privados com padrões próprios de qualidade para produtores orgânicos socialmente sustentáveis, bem como a assistência diante de desastres naturais ou o combate à lavagem de dinheiro, à corrupção e ao financiamento do terrorismo.

\section{A questão do reconhecimento das fontes jurídicas pós- nacionais construídas por atores privados autônomos em relação à ação estatal}

Sobre a viabilidade dessas manifestações jurídicas como novas fontes do direito internacional, cumpre destacar algumas questões levantadas pela doutrina, começando pelo papel dos entes produtores desse direito.

Não se trata de uma questão de resposta fácil, porquanto o termo "fonte do direito internacional" está muito arraigado a uma concepção precisa entre os

36 OST, F; KERCHOVE. De la pyramide an reseau: pour une théorie dialectique du droit. Bruxelles: Públications des Facultés Universitaires Saint-Louis, 2002, p. 74-76.

37 VARELLA, Marcelo Dias. Internacionalização do direito: direito internacional, globalização e complexidade. 2012. 606 f. Dissertação (Tese de Livre-docência) -- Faculdade de Direito, Universidade de São Paulo, São Paulo. f. 466-468. internacionalistas e vinculada ao art. 38 do Estatuto da Corte Internacional de Justiça. Dessa forma, como essas novas manifestações não estão elencadas no referido catálogo, seria possível negar seu reconhecimento de plano. Nesse caso, entretanto, dever-se-ia pressupor que todas as transformações ocorridas no mundo nos últimos oitenta anos pouco alteraram o direito internacional ou que o Estatuto da Corte é uma espécie de bíblia sagrada, resultante de uma vontade legislativa divina que regula o mundo! ${ }^{38}$

O direito internacional no contexto pós-moderno não é mais visto da maneira tão "internacional" como o via a doutrina clássica. O direito internacional pósmoderno é o instrumento jurídico necessário à regulação do sistema internacional, tanto o interestatal, herança do direito internacional clássico, quanto em relação aos novos atores. Conquanto ainda seja pouco claro quais são e como atuam, é certo que essa fragmentação e esse aumento do número de agentes caracterizam o tempo (histórico) e o contexto (cultural) que se denomina pós-moderno. $\mathrm{O}$ fenômeno de ruptura e renovação aconteceu em outras épocas e esse modelo de direito internacional criado e controlado exclusivamente por Estados não mais responde à realidade em que a correspondente evolução do direito internacional se terá de construir. A pós-modernidade em direito internacional se traduz naquilo que se convencionou chamar de "privatização do direito internacional", ou seja, um quadro institucional e normativo mais extenso e complexo. ${ }^{39}$

Todavia, caso se entenda haver novas fontes do direito internacional, deve-se pressupor que os atores que produzem tais fontes são sujeitos do direito. Portanto, o problema é que, se todos são sujeitos do direito internacional, ninguém é sujeito do direito internacional. $\mathrm{O}$ próprio conceito de sujeito perde sua substância e seu sentido. A consequência seria a desconstrução dos conceitos jurídicos tradicionais do direito internacional, sem solução última. ${ }^{40}$

38 VARELLA, Marcelo Dias. Internacionalização do direito: direito internacional, globalização e complexidade. 2012. 606 f. Dissertação (Tese de Livre-docência) -- Faculdade de Direito, Universidade de São Paulo, São Paulo. f. 436- 437, 453.

39 ACCIOLY, Hildebrando; SILVA, Geraldo Eulálio do Nascimento; CASELLA, Paulo Borba. Manual de direito internacional público. 16. ed. São Paulo: Saraiva, 2008. p. 224-227.

40 VARELLA, Marcelo Dias. Internacionalização do direito: direito internacional, globalização e complexidade. 2012. 606 f. Dissertação (Tese de Livre-docência) -- Faculdade de Direito, Universidade de São Paulo, São Paulo. f. 453, 455. 
Ademais, uma ordem legal fragmentada confere aos Estados poderosos uma desejada flexibilidade. Num mundo em rápida mudança em que nem mesmo eles sabem onde seus interesses estarão no futuro, a existência de várias instituições concorrentes retira a necessidade de se comprometerem irrevogavelmente com qualquer uma delas. Isso os ajuda a administrar o risco, e aumenta o seu já substancial poder de barganha. Nesse contexto, as instituições internacionais estão conscientes de que os Estados poderosos podem se recusar a aceitar suas determinações, caso não os agrade, e procurar outra qualquer no futuro. Essa vulnerabilidade aproxima, mais do que deveria, as instituições aos interesses dos Estados poderosos e reduz a probabilidade de que alguma delas cresça suficientemente independente para questionar seriamente a responsabilidade deles. ${ }^{41}$

Além disso, a capacidade de criar novas instituições ou de escolher entre as existentes aquela cujas determinações lhe serão mais favoráveis permite aos Estados poderosos alcançarem um alto grau de comprometimento - e uma boa reputação - que de outra maneira, ou seja, com menos razões para cooperar, não conseguiriam. ${ }^{42} \mathrm{Um}$ dos aspectos mais característicos do comportamento hegemônico é que os mesmos atores poderosos rechaçam o direito por eles criado quando esse direito produz igualdade e estabilidade internacionais. ${ }^{43}$

Outro óbice à existência de um sistema jurídico transnacional, paralelo aos sistemas estatais, diz respeito à possibilidade de autovalidação das normas privadas.

Em virtude da importante influência do positivismo, na maioria dos sistemas jurídicos, o processo de validação de uma norma obedece a uma lógica exclusivamente formal. Esse processo é unilateral, ou seja, respeita um critério intrassistêmico; absoluto, isto é, a regra é completamente válida ou inválida; e hierarquizado. ${ }^{44}$

41 BENVENISTI, E.; DOWNS, G. W., The empires's new clothes: political economy and the fragmentation of international law. Stanford Law Review, v. 60, n. 2, p. 595-634, 2007.

42 BENVENISTI, E.; DOWNS, G. W., The empires's new clothes: political economy and the fragmentation of international law. In: Stanford Law Review, v. 60, n. 2, p. 595-634, 2007.

43 KRISCH, Nico. International law in times of hegemony: unequal power and the shaping of the international legal order. European Journal of International Law, p. 369-378, 2005.

44 OST, F. Legal system between order and disorder. Oxford: Orford University Press, 1994.p. 98.
A seu turno, a validação de normas jurídicas privadas segue regras próprias desvinculadas dos legislativos nacionais. São os próprios atores envolvidos naquele subsistema, especificamente, a reputação de seus "legisladores" e a capacidade deles coordenarem instituições representativas. Numa linha positivista, as redes privadas não seriam consideradas como direito, muito menos como direito internacional, pois, para Kelsen, no direito estatal, a legitimidade da norma está sempre na norma de hierarquia superior. Em última instância, na norma fundamental, que encontra sua validade em uma norma primária fundamental hipotética, objetivamente identificada. Mesmo Verdross que identifica a validade da norma fundamental no pacto social (vontade), também de natureza hipotética, em atenção a pressupostos teóricos contratualistas, como em Rousseau, a possibilidade de uma autovalidação do contrato como criador de regras jurídicas seria um paradoxo, porque não se relaciona com a validade formal, nem com um pacto social originário, nem mesmo com a análise objetiva do comportamento histórico dos atores primários do direito internacional (Estados). ${ }^{45}$

A respeito da produção normativa sem soberania, permaneceu latente, por séculos, o estranho paradoxo da autovalidação do contrato e da organização, em um curioso crepúsculo, cujas razões são históricas: o Estado-nação, sua constituição e suas leis forneceram a distinção entre legislação e adjudicação, aparentemente capaz de absorver todas as formas de "produção normativa privada", escondendo o paradoxo da autovalidação das normas não-oficiais. Portanto, seu advento não é fruto de uma descoberta ingênua da jurisprudência pós-moderna, mas da dureza da realidade social que tornou esse paradoxo visível, isto é, a globalização fragmentada. A soberania legal não sucumbiu pelo ataque da teoria legal, senão das práticas legais. ${ }^{46}$

As alternativas ao direito internacional formal são várias: (i) consultas informais entre agências governamentais, cujas decisões são implementadas por meio de seus respectivos direitos domésticos; (ii)

45 VARELLA, Marcelo Dias. Internacionalização do direito: direito internacional, globalização e complexidade. 2012. 606 f. Dissertação (Tese de Livre-docência) -- Faculdade de Direito, Universidade de São Paulo, São Paulo. f. 302, 463.

46 TEUBNER, G. The King's many bodies: the selfdescontruction of law's hierarchy. Law and Society Review, v. 31, n. 4, p.763-787, 1997. 
instituições não obrigatórias que permitem os governos compartilharem interesses comuns em relação aos de outros Estados; (iii) acordos entre governos e atores privados; (iv) delegação dos governos aos atores privados para atuarem em áreas onde aqueles não querem ou estimam mais adequada a ação destes. ${ }^{47}$

No entanto, esses paradoxos podem ser afastados, consoante uma análise em três níveis. Em relação à hierarquia: esses direitos contratuais criam regras primárias com seu conteúdo básico, mas também regras secundárias (no sentido de Hart) que colocam os contornos de validade para as primeiras; ou regras secundárias (no sentido kelseniano, a partir da sanção de exclusão do sistema). No tempo, inserem-se em um processo que valida atos anteriores ao contrato e subjugam-se a atos posteriores (como por meio de sistemas de arbitragem), que reforçam sua validade. A hierarquia torna-se reputacional e não organizacional. No tocante à externalização, a validade do contrato é vista com elementos exteriores a ele, mas que não são verdadeiramente exteriores, porquanto foram convencionados, como na arbitragem. Portanto, mecanismos próprios de efetividade, como a arbitragem, alimentam a validação do sistema. Contratos na lex mercatoria, comportamento dos atores na lex desportiva ou na lex eletronica, esses dois últimos com maior grau de centralidade e, assim, maior facilidade de visualização, seriam suficientes para configurar regras de validação, dentro de uma lógica de sistema jurídico em Hart, ou mesmo para identificar o caráter sancionatório, indispensável para Kelsen. Conquanto a ideia de centralidade da produção e aplicação normativa, idealizada por Kelsen, não estejam presentes, a existência de um ordenamento jurídico parece ser constante. ${ }^{48}$

Nesse diapasão, observa-se que, diferentemente do sistema tradicional, as sanções podem vir dos próprios atores $\mathrm{e}$, inclusive, excluir aqueles que transgridam o direito posto. Uma empresa que não cumpra as normas da lex mercatoria, e, portanto, apresente um problema em um contrato específico, não poderá mais contratar com todas as demais, caso seja excluída de toda cadeia produtiva pode excluir uma empresa, isto é, a sanção vem de toda a rede de empresas. Se, por um lado, não

47 SLAUGHTER, A. M. The new world order. Princeton: Princeton University Press, 2004.

48 VARELLA, Marcelo Dias. Internacionalização do direito: direito internacional, globalização e complexidade. 2012. 606 f. Dissertação (Tese de Livre-docência) -- Faculdade de Direito, Universidade de São Paulo, São Paulo. f. 46, 464. há mecanismos efetivos para uma indenização por eventuais problemas causados, pela impossibilidade da expropriação ou do uso de violência pela cadeia produtiva privada, por outro, a sanção imposta, qual seja, a exclusão, é, tantas vezes, suficiente para fechar a empresa que cometeu o ilícito. Da mesma forma, a ocorrência de doping em campeonatos internacionais leva à exclusão de um jogador que não será punido apenas no país onde praticou o ilícito; ao contrário, sua carreira pode ser muito mais prejudicada do que se dependesse de ordenamentos jurídicos estatais. ${ }^{49}$

O mais exitoso caso de lei sem Estado foi o da lex mercatoria, uma ordem jurídica transnacional de mercados globais criada à parte do direito nacional e internacional. Lex mercatoria refere-se a um rico fundo de práticas comerciais, formado sob as condições caóticas do mercado global ou, alguém poderia dizer, das práticas impostas pelos interesses econômicos predominantes. Contratos celebrados por empresas multinacionais não suscetíveis à jurisdição ou à lei nacional, mas à arbitragem internacional e à lei comercial transnacional, independentes de qualquer direito nacional. Diante disso, aventam-se algumas questões: As cortes nacionais deveriam reconhecer a "justiça privada" da lex mercatoria como um novo direito positivo com validade transnacional? Poderia tal fenômeno normativo ambíguo - que está "entre e além" dos direitos dos Estados-nação e, ao mesmo tempo "entre e além" do direito e da sociedade - ser aplicado por órgãos arbitrais de acordo com as regras do direito internacional privado? Conteria regras distintas e princípios próprios? Certamente, uma nova prática legal, com direitos substantivo e adjetivo próprios, que não pode ser integrada na hierarquia tradicional do direito nacional ou internacional, ao contrário, se esquivam de pretensões regulatórias do direito nacional e internacional e exercitam sua própria soberania. Essa é a diferença fundamental entre a lex mercatoria e outras formas contratuais que operam e apenas existem dentro da hierarquia legal..$^{50}$

A internacionalidade do mercado global demanda alguma forma de unificação e, por isso, ressurgiu a

49 VARELLA, Marcelo Dias. Internacionalização do direito: direito internacional, globalização e complexidade. 2012. 606 f. Dissertação (Tese de Livre-docência) -- Faculdade de Direito, Universidade de São Paulo, São Paulo. f. 464- 465.

50 TEUBNER, G. The King's many bodies: the selfdescontruction of law's hierarchy. Law and Society Review, v. 31, n. 4, p. 763-787, 1997. 
lex mercatoria, um direito além do Estado, uniforme, transnacional, não territorial, produzido de maneira descentralizada por agentes econômicos com poder de influência cada vez maior, fruto de um processo horizontal e sem hierarquia em relação aos direitos nacionais dotado de flexibilidade (mas que não se confunde com um direito indeterminado), apto a atender às exigências do mercado e marcado pelo triunfo de um pluralismo jurídico inerente à complexidade das relações que se instauram na órbita econômica, todavia, com pouco poder de coerção e ausência de sanções, o que, por sua vez, não se traduz em falta de efetividade. ${ }^{51}$

Entretanto, lex mercatoria, o direito transnacional das relações econômicas, é apenas um dos inúmeros casos de direito global em que a Soberania Política perdeu seu poder. O desenvolvimento de um direito global próprio não se dá somente no campo econômico, mas em diversos setores da sociedade mundial, isolados do Estado, da política internacional e do direito internacional. Direito global sem Estado pode ser encontrado também na lex laboris internationalis, empresas e sindicatos como atores particulares produtores de leis. Padrões técnicos e auto-regulação profissional coordenados globalmente com uma mínima intervenção da política internacional oficial. Similarmente, no campo da ecologia, há tendências de globalização legal sem instituições estatais. Até mesmo no campo dos esportes, discute-se a emergência de uma lex sportiva internationalis..$^{52}$

Os subsistemas da lex desportiva e da lex eletronica são os que apresentam a maior autonomia. Uma liga desportiva pode proibir a participação de um atleta em competições internacionais; pelo desrespeito a uma norma privada paraestatal, ficará afastado das competições, remanescendo inócuo qualquer recurso a um Judiciário nacional. A seu turno, o sistema de regulação da internet é capaz de desativar um sítio que transgrida padrões mínimos estipulados pelas regras pertinentes. ${ }^{53}$

51 TOMAZET'TE, Marlon. Internacionalização do direito além do Estado: a nova lex mercatoria e sua aplicação. Revista de direito internacional. Brasília, v. 9, n. 4, p. 93-121, 2012. p. 111-114, 118.

52 TEUBNER, G. The King's many bodies: the selfdescontruction of law's. Law and Society Review, v. 31, n. 4, p. 115-136, 1997. p. 770.

53 OST, F; KERCHOVE. De la pyramide an reseau: pour une théorie dialectique du droit. Bruxelles: Públications des Facultés Universitaires Saint-Louis, 2002, p. 84.
Essa "rede de interesses", emergente e heterárquica, depende do consentimento dos usuários da internet e deve considerar a complexidade presente nas expectativas normativas e nas normas sociais geradas nos processos privados envolvidos. O procedimento de "notificar e comentar" poderia ser um elemento de regulação nos moldes do direito privado. Não se deve olvidar que a fragmentação das formas de uso, o advento de estratégias personalizadas de publicidade e a sobreposição de redes são uma boa razão para pensar a proteção de um novo tipo de "consumidor", um tipo híbrido de "cidadão da internet" que atua de diferentes maneiras no ambiente virtual. A vantagem desse procedimento não consistiria apenas na devida tutela de direitos, outrossim e antes de tudo, no reconhecimento de que a sociedade pós-moderna precisa de uma nova estrutura institucional mais compatível com as rápidas mudanças das normas sociais do que com normas

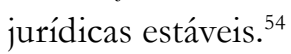

Em outras palavras, as relações jurídicas de controle criam novas figuras e formas de responsabilização independentes do Estado. Os prejuízos sofridos pela quebra de valores da própria rede por um ator ou grupo de atores passam a ser concebidos como um prejuízo de conjunto, uma vez que os objetivos dos atores estão centrados na própria manutenção e expansão da rede. Os sistemas de punição, agora privados, consistem na exclusão de atores ou conjunto de atores que se mostram contrários aos objetivos coletivos ou apenas para a consecução ótima dos resultados pretendidos. Especificamente no caso da lex mercatoria, uma rede pluriempresarial, diferente de pessoas naturais ou pessoas coletivas, em dois aspectos principais: a imputação múltipla, que ganha espaço sobre a imputação unitária, e a autonomização policêntrica, que avança sobre a ideia de personificação. A lógica desse subsistema se afasta dos interesses dos Estados de nacionalidade das empresas envolvidas. A responsabilidade do grupo apenas poderia ser atingida a partir da ideia de sua existência como sujeito diferente dos atores individuais e a aceitação de uma imputação casuística e flexível, cumulativa ou alternativa à tradicional imputação de empresas. ${ }^{55}$

54 LADEUR, Karl-Heinz. New institutions for the protection of privacy and personal dignity in internet communication: "information broker", "private cyber courts" and network of contracts. Revista Brasileira de Políticas Públicas, Brasília, v. 10, n. 1, p. 281-296, 2013. p. 292-294, 296.

55 VARELLA, Marcelo Dias. Internacionalização do direito: direito internacional, globalização e complexidade. 2012. 606 f. Dissertação 
Portanto, por meio de um movimento centrípeto, redes de atores privados criam normas próprias de conduta e mecanismos específicos de sanção que engendram expectativas de cumprimento suficientes para garantir legitimidade e efetividade ao sistema. Dessa maneira, possuem maior ou menor efetividade, consoante a legitimidade obtida por seus procedimentos próprios ou por suas capacidades de sanção. ${ }^{56}$

Todavia, não se deve olvidar que, esses expedientes produzem custos proibitivamente altos que os países mais fracos têm de pagar para formarem uma necessária coalizão política, a fim de aumentarem seu poder de barganha com as contrapartes poderosas. $\mathrm{O}$ caráter restrito e a pouca integração das organizações multilaterais, o lento ritmo em que as instituições internacionais têm sido democratizadas e a falta de redistribuição de poder entre Norte e Sul confirmam o impacto dessas estratégias. ${ }^{57}$

É possível assim sintetizar o problema: acordos jurídicos aumentam a integração das redes por meio de um regime compromissivo e com mecanismos de coordenação dados pela imposição de adequadas obrigações. Não há dúvida de que a conectividade das redes em um mundo descentralizado - o maior símbolo das relações em rede - é fortalecida pelas normas jurídicas apropriadas. Entretanto, [as relações em rede implicam uma nova dinâmica de divisão: a diferença entre efeitos factuais vinculativos e nãovinculativos; ou a separação entre a esfera contratual e a esfera reticular; ou pela divisão entre uma estrutura contratual e posterior concretização, ou a distinção entre uma orientação individual e outra coletiva, ou, ainda, pela diferença entre competição e cooperação. ${ }^{58}$

Finalmente, a respeito da possibilidade de vincular os Estados a mecanismos jurídicos particulares, numa primeira análise, se diria que normas criadas por redes privadas independentes dos Estados, mormente transnacionais, não geram obrigações para os Estados

(Tese de Livre-docência) -- Faculdade de Direito, Universidade de São Paulo, São Paulo. f. 307.

56 VARELLA, Marcelo Dias. Internacionalização do direito: direito internacional, globalização e complexidade. 2012. 606 f. Dissertação (Tese de Livre-docência) -- Faculdade de Direito, Universidade de São Paulo, São Paulo. f. 296-297.

57 BENVENISTI, E.; DOWNS, G. W., The empires's new clothes: political economy and the fragmentation of international law. Stanford Law Review, v. 60, n. 2, p. 595-634, 2007. p. 599, 610.

58 TEUBNER, G. And if i by beelzebub cast out devils: an essay on the diabolics of network failure. German Law Journal, v. 10, n. 4, p. 115-136, 2009. p. 133. onde atuam, senão para os próprios elementos da rede, mesmo que seus efeitos sejam similares aos de atos estatais. Contudo, é importante colocar esse novo fenômeno em um quadro mais amplo, mesmo que se chegue às mesmas conclusões.

O direito pós-nacional é construído pelas interações entre diferentes camadas nas esferas nacional, internacional e transnacional, com diferentes racionalidades, fenômeno nomeado de "policontextualização do direito". Dessa forma, esse novo direito formado por uma ampla rede normativa não coincide tampouco deve ser confundido com o tradicional direito internacional. ${ }^{59}$

Agora os atores do direito internacional, além do Estado e das Organizações Internacionais, ganham mais densidade no plano internacional, com capacidade de criar normas imponíveis a grupos humanos, por vezes mais densas e efetivas do que as normas interestatais. $\mathrm{O}$ direito internacional torna-se mais especializado e mais complexo, conforme a própria sociedade global se especializa e se torna mais complexa. Nesse caso, não significa que essas normas sejam cogentes para os Estados, mas seriam normas de um direito pósnacional, criando-se novas fontes do direito, mas não do direito internacional, que se tornam imponíveis de formas distintas a diferentes atores que compõem uma nova esfera global. $\mathrm{O}$ direito pós-nacional viria principalmente desses conjuntos de relação globais (ou transnacionais), mas não necessariamente inter(nacionais). Não é conveniente falar em novas fontes do direito internacional, mas em novas fontes de um direito pós-nacional ou de um conjunto de novos elementos cognitivos que servem de sustentação de um direito internacional, sem o qual esse direito simplesmente inexiste na realidade atual. ${ }^{60}$

Embora a autonomia seja a base do direito privado, não há uma estrutura organizacional para tutelar as relações em rede. Não é possível supor que institutos jurídicos autônomos produzidos pelos nós da rede gerem comportamentos obrigatórios uma vez que se fundam não num acordo específico, mas em comportamentos factuais decorrentes de "contatos sociais", cuja vagueza do termo constitui obstáculo ao

59 TEUBNER, G. Global law without a state. Hants: Dartmouth, 1997. p. 770.

60 VARELLA, Marcelo Dias. Internacionalização do direito: direito internacional, globalização e complexidade. 2012. 606 f. Dissertação (Tese de Livre-docência) -- Faculdade de Direito, Universidade de São Paulo, São Paulo. f. 296, 455 - 456. 
desenvolvimento de regras adequadas. Sem um centro, sem uma liderança, sem uma administração unificada e sem uma única representação autorizada, os vários nós das relações em rede são atores coletivos que operam, simultaneamente, em seu próprio nome e em nome da rede. Eles produzem, por meio de ações individuais, compromissos coletivos, cujos efeitos sociais devem ser reforçados por regras jurídicas. Contudo, devido a essa confusa e estranha fragmentação do coletivo em múltiplos eixos individuais de decisões, as relações em rede não têm sido adequadamente absorvidas pela lei. ${ }^{61}$

\section{Considerações finais}

Constam do diversificado arcabouço normativo do direito pós-nacional uma modalidade de normas edificadas por entes transnacionais privados, tomando seus próprios interesses como se fossem públicos, abdicando de regular apenas interesses individuais e passando a concorrer com o direito público na tutela de interesses coletivos.

O padrão jurídico clássico, caracterizado por normas produzidas por entes soberanos e hierarquicamente organizadas dentro da racionalidade do sistema, cede espaço para uma multiplicidade de subsistemas jurídicos autônomos, sem coordenação entre si e com sanções próprias, cujas relações são marcadamente heterárquicas. Assim, o fundamento de validade desses mecanismos migra da lógica democrática para a estabilidade das relações em rede. Atualmente, há grande debate jurídico relativo ao reconhecimento de novas fontes jurídicas criadas mediante relações heterárquicas e autovalidadas por atores privados - como indivíduos e empresas, na qualidade de novos sujeitos de direito internacional - vis-à-vis os fundamentos do direito internacional consagrados, desde o século XVIII, a partir da perspectiva tanto da teoria positivista contemporânea, quanto da teoria do direito natural.

A validação de normas jurídicas privadas ocorre fora dos domínios do Estado-Nação, especificamente, no comportamento e na credibilidade dos atores, verdadeiros legisladores, envolvidos em determinado subsistema jurídico, a exemplo da lex desportiva ou da lex eletronica. Antigos dilemas quanto à hierarquia são resolvidos se entendermos que esses direitos contratuais

61 TEUBNER, G. And if i by beelzebub cast out devils: an essay on the diabolics of network failure, In: German Law Journal, v. 10, n. 4, p. 115-136, 2009, p. 118, 122-123, 130. criam regras primárias convencionadas entre as partes, como se dá no âmbito da arbitragem. Até mesmo a questão de um sistema de coerção é solucionada com a aplicação de sanções pelos próprios atores entre si, como se dá na lex mercatoria. Todavia, se essa ampla rede normativa privada, por um lado, não se traduz no clássico direito internacional, por outro, tampouco permite que se anuncie o advento de um novo direito internacional.

\section{Referências}

ACCIOLY, Hildebrando; SILVA, Geraldo Eulálio do Nascimento e; CASELLA, Paulo Borba. Manual de direito internacional público. 16. ed. São Paulo: Saraiva, 2008.

BENVENISTI, E.; DOWNS, G. W., The empires's new clothes: political economy and the fragmentation of international law. Stanford Law Review, v. 60, n. 2, p. 595-634, 2007.

BURKE-WHITE, W., International legal pluralism. Michigan Journal of International Law, v. 25, p. 963-979, 2004.

DELMAS-MARTY, M. Les forces imaginantes du droit. Le pluralisme ordonné, Paris: Seuil, 2005. v. 2

ELIAS, Fernando Lopes Ferraz. Fontes do direito: o direito internacional como a grande norma kelseniana. In: CONGRESSO BRASILEIRO DE DIREITO INTERNACIONAL. 7., 2009, Curitiba. Anais... Curitiba: Juruá, 2009. v. 17.

HART, H. O conceito de direito. 3. ed. Lisboa: Fundação Calouste Gulbenkian, 1994.

KANT, Imannuel. A pazperpétua. Tradução Marco A. Zingano. Porto Alegre: L\&PM, 1989.

KELSEN, Hans. Teoria pura do direito. Tradução: João Baptista Machado. 6. ed. São Paulo: Martins Fontes, 1998.

KOSKENNIEMI, Martti. From apology to utopia: the structure of international legal argument, reissue with a new epilogue. Cambridge: Cambridge University, 2005.

KOSKENNIEMI, Martti; LEINO, Päivi. Fragmentation of international law? postmodern anxieties. Leiden Journal of International Law, v. 15, p. 553575,2002 . 
KRISCH, Nico. Beyond constitucionalism: the pluralism structure of posnational law. Oxford: Oxford University Press, 2010.

KRISCH, Nico. International law in times of hegemony: unequal power and the shaping of the international legal order. European Journal of International Law, p. 369-378, 2005.

LADEUR, Karl-Heinz. New institutions for the protection of privacy and personal dignity in internet communication: "information broker", "private cyber courts" and network of contracts. Revista Brasileira de Políticas Públicas. Brasília, v. 10, n. 1, p. 281-296, 2013.

MELlO, Celso Duvivier de Albuquerque. Curso de direito internacional público. 12. ed. Rio de Janeiro: Renovar, 2000. 2v.

OST, F. Legal system between order and disorder. Oxford: Orford University Press, 1994.

OST, F; KERCHOVE. De la pyramide an resean: pour une théorie dialectique du droit. Bruxelles: Públications des Facultés Universitaires Saint-Louis, 2002.

SLAUGHTER, A. M. The new world order. Princeton: Princeton University Press, 2004.

TEUBNER, G. And if i by beelzebub cast out devils: an essay on the diabolics of network failure. German Law Journal, v. 10, n. 4, p. 115-136, 2009.
TEUBNER, G. Constitutional fragments. Oxford: OUP, 2012.

TEUBNER, G Droit et réflexivité: l'auto-référence en droit et dans l'organisation. Tradução de N. Boucquey. Paris-Bruxelles: Story-LGDJ, 1994.

TEUBNER, G Global law without a state. Hants: Dartmouth, 1997.

TEUBNER, G. Les multiples corps du roi: l'autodestruction de la hiérarchie du droit, In: Pbilosopbie du droit et droit économique, quel dialogue? Paris: Frison-Roche, 1999.

TEUBNER, G. The king's many bodies: the selfdescontruction of law's hierarchy. Law and Society Review, v. 31, n. 4, p. 763-787, 1997.

TOMAZETTE, Marlon. Internacionalização do direito além do Estado: a nova lex mercatoria e sua aplicação. Revista de direito internacional. Brasília, v. 9, n. 4, p. 93-121, 2012.

TURGIS, Sandrine. Les Interactions entre les norme internationales relatives aux droits de la personne. Paris: A. Pedone, 2010.

VARELLA, Marcelo Dias. Internacionalização do direito: direito internacional, globalização e complexidade. 2012. 606 f. Dissertação (Tese de Livre-Docencia) -- Faculdade de Direito, Universidade de São Paulo, São Paulo, 2012. 
Para publicar na Revista de Direito Internacional, acesse o endereço eletrônico www.rdi.uniceub.br ou www.brazilianjournal.org.

Observe as normas de publicação, para facilitar e agilizar o trabalho de edição. 